\title{
Governança democrática da segurança pública O caso da educação policial no Brasil
}

\author{
Democratic governance and public security
}

The case of police education in Brazil

Paula Poncioni*

\begin{abstract}
Resumo: Este artigo busca analisar a experiência de governança da Secretaria Nacional de Segurança Pública (Senasp) no sentido de direcionar, coordenar e avaliar as ações e metas propostas pelas políticas públicas na área da segurança para o incremento de um novo paradigma - o da segurança pública com cidadania - na chamada "educação policial". Para tanto, foi realizada pesquisa bibliográfica e de campo. A pesquisa bibliográfica compreendeu o exame da literatura, nacional e internacional, sobre polícia, profissionalismo, governança, políticas públicas e democracia. A pesquisa de campo envolveu basicamente o exame da documentação oficial da Secretaria Nacional de Segurança Pública/Ministério da Justiça (Senasp/MJ), especialmente aquela dirigida à área de "educação policial", produzida no período compreendido entre 2003 e 2010. Palavras-chave: Governança. Política pública de segurança. Educação policial.
\end{abstract}

Abstract: This paper analyzes the experience of governance of the National Secretariat of Public Security (Senasp) to direct, coordinate and evaluate the actions and targets proposed by public policies in the area of security for the increment of a new paradigm - the public safety with citizenship - into the so-called "police education". To reach this, bibliographical research and field work were accomplished. The literature review included an examination of literature, nationally and internationally, on police professionalism, governance, public policy and democracy. The field work involved primarily an analysis of the official documentation of the National Secretariat of Public Security/Ministry of Justice (Senasp/MJ), especially addressed the area of "police education" produced in the period between 2003 and 2010.

Keywords: Governance. Security public policy. Police education.

* Doutora em Sociologia pela USP e professora da Escola de Serviço Social da Universidade Federal do Rio de Janeiro, no Rio de Janeiro, RJ, Brasil < pponcioni@terra.com.br>.

\begin{tabular}{|l|l|l|l|l|l|}
\hline Civitas & Porto Alegre & v. 13 & n. 1 & p. $48-55$ & jan.-abr. 2013 \\
\hline
\end{tabular}




\section{Introdução}

Desde os anos 1960, em diferentes contextos nacionais, verificase a ocorrência de alguns temas e problemas semelhantes decorrentes da vida urbana e das relações sociais que a caracteriza - a segregação social, a incorporação de minorias, a mobilidade social e cultural, o crescimento contínuo da criminalidade e da violência -, destacando-se o último como um dos mais graves problemas sociais urbanos no final do século 20 e começo do 21 .

Neste cenário, chama a atenção o perfil diferenciado na forma como vem se dando a intervenção do estado, nos diferentes países, no que diz respeito às ações públicas para equacionar os graves problemas relacionados à ordem e segurança públicas.

No Brasil, vale à pena lembrar que é somente a partir de 2000 que se organiza, ao nível do estado, uma representação sistemática e substantiva sobre segurança pública resultando no primeiro Plano Nacional de Segurança Pública - PNSP, seguido de dois outros planos: o Plano de Segurança Pública para o Brasil (2003) e o Plano Nacional de Segurança Pública com Cidadania - Pronasci (2007). ${ }^{1}$

Pode-se constatar que, ao longo desses três planos, foram realizadas algumas importantes tentativas de criação de um sistema de governança democrática da política pública de segurança, ${ }^{2}$ pela cooperação entre as diferentes esferas de governo por meio do estabelecimento de metas e objetivos comuns entre os diversos órgãos de segurança pública, com vistas a priorizar o atendimento eficiente às demandas da sociedade e o impacto na redução da violência e da criminalidade.

Nesta direção, ressaltam-se iniciativas as quais, a exemplo do que ocorreu nas políticas destinadas à efetivação dos outros direitos sociais previstos na Constituição Federal, procuraram conjugar a participação de trabalhadores e gestores vinculados a este setor, bem como representantes da sociedade civil, para a busca de soluções para a área. ${ }^{3}$

O Conselho Nacional de Segurança Pública - Conasp, delineado pelo Decreto no 98.936/1990 e, mais tarde, instituído pelo Decreto nº 2.169/1997, foi um primeiro passo nesse sentido. A convocação da 1르 Conferência Nacional

1 Para conhecer o percurso dos diferentes planos de segurança pública no país, consultar Adorno (2009) e Tavares dos Santos (2009).

2 Sobre as diversas acepções da noção de governança, ver a propósito: Proença; Muniz; Poncioni (2009).

3 Ver a respeito sobre o assunto: Kopittke; Torelly (2008). 
de Segurança Pública, em 2008, bem como a reestruturação do Conasp, levada a efeito por meio do Decreto $\mathrm{n}^{-} 6.950 / 2009$, abriram novas oportunidades de avanço objetivando estabelecer, a partir de temas-chave, o debate sobre as alternativas para a gestão da segurança pública com a participação da sociedade.

$\mathrm{Na}$ área da chamada "educação policial", verifica-se que a Secretaria Nacional de Segurança Pública do Ministério da Justiça, ${ }^{4}$ criada em 1998, teve o seu protagonismo incrementado, agindo como indutora e articuladora das políticas públicas na área, exercendo a coordenação, ao nível nacional, para a implantação dos planos nacionais de segurança pública, com a parceria de diferentes atores como Organizações Não-Governamentais, Institutos de Pesquisa e Universidades - públicas e privadas - para citar os mais importantes.

Sob a sua batuta, destacam-se algumas iniciativas como a criação da "Matriz Curricular Nacional para o ensino policial", lançada pela Senasp, em 2003, a concessão de bolsas-formação para policiais civis e militares, a realização dos cursos de especialização promovidos pela Rede Nacional de Altos Estudos em Segurança Pública (Renaesp), criada em 2005, em parceria com universidades públicas e privadas para profissionais da área e da sociedade civil organizada e os cursos de educação à distância através dos telecentros. Salienta-se, ainda, algumas ações como a realização dos cursos de Direitos Humanos para policiais, dos fóruns, dos seminários, das mesas-redondas, entre outros, desenvolvidos em grande parte do território nacional.

A criação da Matriz Curricular Nacional para o ensino policial parece finalmente alçar a formação profissional de policiais à agenda governamental, com o status de uma política pública, considerando-se o lugar privilegiado na escolha de alternativas e propostas para a problemática que envolve o desempenho de policiais para a efetivação de uma segurança pública "cidadã" no país.

A Matriz oferece, a partir de uma definição institucional do profissional de segurança pública, no caso dos policiais, os parâmetros técnicos para a mudança dos referenciais teórico-práticos da formação profissional; propõe romper com os paradigmas vigentes da formação profissional de policiais, pautado fundamentalmente em um "modelo profissional policial tradicional", que mescla princípios militaristas e legalistas para o controle do crime, para a adoção de um modelo profissional policial de tipo "novo", que enfatiza o serviço público, a discrição do policial informada por alto nível de educação

\footnotetext{
4 Ver a respeito: $<$ http://www.mj.gov.br $>$.
} 
e treinamento, e a busca de uma relação mais estreita entre a polícia e a comunidade, característico das sociedades democráticas (Poncioni, 2004).

Outra significativa iniciativa é a Rede Nacional de Altos Estudos em Segurança Pública, que é um projeto de educação permanente voltado aos profissionais de segurança pública, bem como aos demais profissionais interessados e atuantes nesta área. A Rede se constitui a partir da parceria com instituições de ensino superior (IES) que promovem cursos de pós-graduação lato sensu sobre diferentes temas relacionados à Segurança Pública em duas modalidades: presencial e a distância.

De acordo com os preceitos da Senasp, a Rede foi criada para oferecer aos profissionais da área a oportunidade de aprofundar o conhecimento em segurança pública e formar pensadores e gestores especialistas neste segmento.

Além disso, em 2010, a Senasp criou o "Selo Renaesp de Educação em Segurança Pública", como uma forma de dar reconhecimento às Instituições de Ensino Superior que oferecem cursos inovadores e que contribuem com o processo de pensar e fazer segurança pública no Brasil.

Certamente o papel político desempenhado pela Senasp, no plano da condução de uma política pública, coloca-a como um ator importante na articulação de alternativas que considerem não apenas o nível da ação do Estado nas distintas esferas governamentais, mas também a incorporação das iniciativas da sociedade numa política de gestão das demandas públicas (Kopittke; Torelly, 2008); insinua-se um cenário promissor para a governança democrática da segurança pública no país.

\section{O "sistema" de governança democrática da política pública de segurança: algumas considerações preliminares}

O exame das propostas e realizações dos planos nacionais de segurança pública revela que, ao longo do período examinado, algumas proposições se mantiveram em relevo, como o incremento da formação e aperfeiçoamento profissional de policiais, sendo incorporadas ao longo dos anos em diversas iniciativas da Secretaria Nacional de Segurança Pública/Ministério da Justiça, com base em alguns relevantes princípios, segundo os quais a segurança pública é um direito do cidadão e a educação configura-se como um dos principais pilares para o aperfeiçoamento técnico e gerencial e o estabelecimento e/ou no aprofundamento do conteúdo democrático de práticas e rotinas das organizações policiais.

Sob esse ponto de vista ressalta-se que, nos últimos anos, houve um esforço de maior amplitude por parte do estado brasileiro no sentido de 
identificar e sistematizar temáticas, preocupações e práticas relacionadas à questão da segurança, bem como de alternativas para viabilizar os objetivos dos planos, constituindo-se uma alavanca para a indução da reforma das polícias brasileiras.

Entretanto, não obstante tenha se observado a intensificação de discussões e iniciativas, com a participação de diferentes atores, a prática da governança pública na área da segurança pública tem apresentado, até o momento, sérias deficiências.

Nos estudos realizados (Poncioni, 2004; 2008) foi verificado que com relação à formação e aperfeiçoamento profissional de policiais, a efetivação do conjunto de diretrizes e ações necessárias para conduzir mudanças que induzam a um "novo paradigma" na formação profissional de policiais brasileiros, vem sendo limitada por alguns impasses a despeito dos esforços envidados pela Senasp. Persiste na área da chamada "educação policial" fragilidades no que diz respeito às ferramentas necessárias - humanas e materiais - para articular as reformulações propostas para a capacitação e aprimoramento dos recursos humanos da polícia.

Em trabalho anterior sobre o processo de formação profissional do policial nas academias de polícia - civil e militar - do estado do Rio de Janeiro (Poncioni, 2004), constatou-se a quase total ausência de diretrizes emanadas por uma política pública para nortear as ações da polícia, com relação especialmente à formação profissional desenvolvida nas academias de polícia, embora estivesse presente em diferentes discursos públicos, inclusive no da própria polícia, a argumentação sobre a necessidade do desenvolvimento de um novo paradigma na socialização profissional de policiais para a assimilação de valores e estratégias mais afinados com o provimento da segurança pública com respeito à cidadania. ${ }^{5}$

Foi verificado, ainda, que não há uma equipe técnica especializada, principalmente de professores qualificados, que atue junto ao ensino, treinamento e supervisão profissional de policiais nas academias de polícia. Além disso, não há bibliotecas, e quando existem nem sempre os títulos são apropriados para os estudos relacionados à segurança pública; não há salas de estudo; não existem laboratórios de informática, dentre outros recursos materiais necessários para a formação e aperfeiçoamento profissional de policiais. ${ }^{6}$

\footnotetext{
5 Apesar de a pesquisa de campo ter se concentrado no Rio de Janeiro, esta não é uma realidade peculiar apenas deste estado da federação, podendo ser generalizada a outros estados brasileiros.

6 Para um estudo sobre o assunto, incluindo outros estados da federação, consultar a respeito: Ministério da Justiça (2006).
} 
Em outra pesquisa (Poncioni, 2008) realizada junto aos policiais, civis e militares, envolvidos com a formação profissional e as autoridades do governo do Rio de Janeiro sobre os impactos das políticas públicas - nacional e estadual - na área de educação policial, verificou-se, ainda, que apesar da menção aos documentos elaborados para a formação profissional básica, como a "Matriz Curricular Nacional para a Formação em Segurança Pública" (Secretaria Nacional de Segurança Pública) e o "Currículo Integrado" para as polícias, civil e militar (Instituto de Segurança Pública - ISP/SSPRJ), não se estabeleceu um amplo debate sobre os modelos policiais profissionais e as estratégias necessárias à transmissão e sedimentação de conhecimentos, valores e comportamentos para nortear uma extensa e profunda reforma na forma de atuação dos operadores de segurança pública, com vistas a incrementar um padrão de excelência e comportamento ético no exercício cotidiano do trabalho dos membros desse grupo ocupacional específico para o cumprimento do mandato policial na sociedade brasileira contemporânea.

Neste sentido, ainda que se verifiquem mudanças nas polícias brasileiras, nos últimos anos, é possível argumentar que, com raras exceções, as mesmas não têm sido marcadas pela combinação entre uma nova concepção do trabalho policial e um treinamento em técnicas e estratégias mais eficientes e responsáveis para o controle mais efetivo do crime e a redução da violência na sociedade brasileira contemporânea. Permanece, em um significativo número de estados brasileiros, uma maneira de conceber o trabalho policial fundamentalmente como "combate ao crime", empregando-se frequentemente o uso intensivo de táticas e procedimentos de "guerra" nas práticas policiais para o "combate ao crime".

Partindo-se dos aspectos levantados no breve cenário esboçado, evidenciase que, por um lado, houve nos últimos anos várias intervenções públicas, a partir principalmente dos planos nacionais de segurança pública, para o incremento de um novo paradigma na área da chamada "educação policial". Mais do que isso, pode-se verificar que essas iniciativas desenvolveram-se em parceria com diferentes atores e setores da sociedade, assinalando uma nova direção, supostamente mais democrática, no que diz respeito à governança da segurança no país. Sem dúvida, constata-se que houve avanços substanciais nesse sentido. Por outro, chama a atenção certas fragilidades na consecução dos propósitos de estabelecer um novo paradigma - o da segurança pública com cidadania - na chamada "educação policial".

Um ponto importante, que embora não tenha sido explorado neste trabalho, diz respeito aos recursos alocados para o Sistema Único de Segurança Pública (Susp), criado em 2003, para articular as ações na área da segurança pública 
e da justiça criminal, que vêm sendo sistematicamente reduzidos ao longo dos últimos anos, comprometendo assim a eficácia da Senasp na prática da governança pública da chamada "educação policial" (cf. Costa; Grossi, 2007).

Some-se a isso, a quase total ausência de monitoramento e avaliação dos programas propostos para a área, o que vem impedindo a gestão adequada dos recursos públicos, a participação do controle público sobre a qualidade do trabalho realizado nas academias de polícia e a efetividade das ações na realidade que se pretende intervir.

Concluindo, constata-se que no cenário nacional perduram ainda os problemas de fragmentação e dispersão das ações dirigidas para a área de segurança pública e, em particular, para um projeto educacional capaz de propiciar, não somente resultados palpáveis em face das demandas para uma política de policiamento, mas também colocar em obra valores que satisfaçam interesses de longo e duradouro alcance institucional e societário.

\section{Referências}

ADORNO, Sergio. Políticas públicas de segurança e justiça penal. Cadernos Adenauer 9 , n. 4, Segurança Pública, Rio de Janeiro: Fundação Adenauer, p. 9-27, jan. 2009.

COSTA, Arthur; GROSSI, Bruno. Relações intergovernamentais e segurança pública: uma análise do fundo nacional de segurança pública. Revista Brasileira de Segurança Pública, v. 1, n. 1, p. 6-20, 2007.

KOPITTKE, Alberto L.; TORELLY, Marcelo Dalmás. Políticas públicas para segurança com participação: esboço sobre a conferência nacional de segurança pública com cidadania. Violência e Controle Social na Contemporaneidade. Anais do $3^{\circ} \mathrm{Ciclo}$ de Estudos e Debates sobre Violência e Controle Social. Porto Alegre: EdiPUCRS, 2008. v. 3, p. 99-114.

MINISTÉRIO da Justiça, Deasp. Bases curriculares para a formação dos profissionais da área de segurança do cidadão (Proposta) - AD/BRA/98/D-32, Programa de modernização do Poder Executivo Federal, Subprograma: Gestão e Desenvolvimento de Recursos Humanos. Componente: Formação de Quadros para Segurança Pública, Projeto: Treinamento para Profissionais da Área de Segurança Pública do Cidadão, Ministério da Justiça, Deasp, Brasília, dez. 1999.

MINISTÉRIO da Justiça, Senasp. Relatório Descritivo. Pesquisa do perfil organizacional das academias e centros de formação das polícias militares e corpos de bombeiros militares no Brasil (2005), dez. 2006.

. Matriz curricular nacional para a formação em segurança pública, Brasília, [2003]. Disponível em: <http://www.mj.gov.br>.

PONCIONI, Paula. Tornar-se policial: a construção da identidade profissional do policial no estado do Rio de Janeiro. Tese (Doutorado) - Programa de Pós-Graduação em Sociologia, Departamento de Sociologia da Faculdade de Filosofia, Letras e Ciências Humanas, Universidade de São Paulo, 2004. 
PONCIONI, Paula. Relatório de pesquisa do Projeto de Pesquisa Um olhar sobre as politicas públicas na área de segurança através da formação profissional do policial, desenvolvido com apoio da Fundação Carlos Chagas Filho de Amparo à Pesquisa do Estado do Rio de Janeiro - Faperj, ESS, UFRJ, 2008 (Relatório final, versão preliminar, mimeo).

PROENÇA JÚNIOR, Domício; MUNIZ, Jacqueline; PONCIONI, Paula. Da governança de polícia à governança policial: controlar para saber; saber para governar. Revista Brasileira de Segurança Pública, São Paulo, v. 3, n. 5, p. 14-50, ago.-set. 2009.

TAVARES DOS SANTOS, José Vicente. Segurança pública e violência no Brasil. Políticas públicas de segurança e justiça penal. Cadernos Adenauer 9, n. 4, Segurança Pública, Rio de Janeiro: Fundação Adenauer, p. 83-95, jan. 2009.

TRIBUNAL de Contas da União. Sumários Executivos. Nova Série Avaliação do Programa Sistema Único de Segurança Pública. Relator Auditor Lincoln Magalhães da Rocha, Brasília, 2005.

Data de recebimento: 29/02/2012.

Data de aprovação: 30/03/2013.

Autora correspondente:

Paula Poncioni

Rua Humaitá, 258, ap. 807

22261-001 Rio de Janeiro, RJ 